\title{
Relationships between deformation and microstructure evolution and minimizing surface roughness after BCP processing in RRR Nb cavitites (DOE DE-FG02-06ER41433)
}

\author{
ILC-Americas University-based Accelerator R\&D Progress Report \\ T.R. Bieler, D. Baars, K.T. Hartwig, C. Compton, T.L. Grimm
}

\section{Project Overview}

Three strategies for improving the surface finish of niobium sheet used in cavities were identified in the funded proposal,

1) Examine how process variables such as crystal orientation and welding affect the "single crystal" material (may be a cost effective alternative to rolled material).

2) Identify effects of rolling variables on surface texture, dislocation density, and recrystallization, to identify optimal conventional rolling approaches.

3) Further reduce the grain size and improve rolling uniformity using equal channel angle extrusion (ECAE) to pre-condition billets before rolling, and evaluate effects on heterogeneity in the microstructure and etching characteristics.

With the budget allocated, we decided to focus on items 1 and 3, which taken together will inform issues related to item 2, and hence obtain the best impact for the resources provided. The following will summarize the progress made on deformed and recrystallized single crystal specimens, and on the effects of ECAE pre-processing of $\mathrm{Nb}$ on microstructure and texture. In this effort, 6 papers were published, and 12 presentations were given. In particular, this research has culminated in a tutorial presentation made on the physical and mechanical metallurgy relevant to $\mathrm{Nb}$ cavity fabrication at the $2008 \mathrm{SRF}$ Materials Workshop (available at http://meetings.nscl.msu.edu/srfmatsci/index.php?id=conference details/Wednesday.php).

Initial Material: The starting condition for making any RRR niobium products are the ingots that contain very large crystals (30-300 $\mathrm{mm}$ grain dimensions in a $\sim 300 \mathrm{~mm}$ diameter ingot). Slices from the ingots used to make prototype single or multi-crystal cavities also provided samples to examine deformation and recrystallization effects. For ECAE processing, $25 \mathrm{~mm}$ square $\mathrm{x} 150 \mathrm{~mm}$ long billets containing not more than a few crystal orientations were used.

Analysis of many conventionally rolled and recrystallized specimens show heterogeneous texture gradients that are never alike. This implies that the deformation characteristics depend on the initial crystal orientations in the starting billet, and hence, every batch of sheet niobium has a different deformation and recrystallization history. Thus the two approaches, 1) of avoiding rolling altogether in the single/multi-crystal approach, and 3) deforming the $\mathrm{Nb}$ severely in a strategic way so that the prior crystal orientation effects are obliterated, provide dramatically contrasting approaches that allow fundamental physical understanding of relationships between niobium forming and surface quality to be identified.

\section{ECAE pre-processing of ingots to obtain controlled texture in sheet metal}

This work was conducted in collaboration with K.T. Hartwig, of Shear Form Inc. which has been built upon work done in a DOE funded phase I SBIR project. Equal Channel Angular Extrusion (ECAE) provides a means to homogenize the microstructure, and engineer a favorable texture before rolling into sheet. ECAE generates uniform severe plastic deformation during each pass ( $\sim 200 \%$ strain for an idealized $90^{\circ}$ angle, assuming simple shear). As the billet cross section does not change during extrusion, one may rotate the billet about its long axis between repeated passes, generating shear on different planes in the sample coordinate system, as 
illustrated in Figure 1 [1]. Thus ECAE enables more opportunities for applying strain in different directions than conventional rolling, providing an ability to control the deformation history to intentionally obtain textures different from those produced by conventional rolling.

Beginning with a coarse-grained ingot (like those used for commercially rolled $\mathrm{Nb}$ ), $25 \mathrm{x}$ $25 \times 150 \mathrm{~mm}$ bars consisting of 1-5 large grains each were processed with several different processing routes at Shear Form Inc. Two alloys were examined, one of reactor grade, and one of high purity with a high RRR value. Three sample textures of preprocessing + annealing of these bars are provided in Figure 2, showing substantially different textures and grain sizes. Annealing was done at $800^{\circ} \mathrm{C}$ for RRR and $1000^{\circ} \mathrm{C}$ for reactor grade material, as recrystallization temperatures differ with purity. The difference between paths $A$ and $B_{c}(B$ with one $180^{\circ}$ rotation) is substantial for the $\mathrm{RG}$ material; the grain size is fine (about $30 \mu \mathrm{m}$ ) for $\mathrm{B}_{\mathrm{c}}$ and large $(\sim 100 \mu \mathrm{m})$ for Route A, even though the annealing conditions were the same. The $\phi_{2}=45^{\circ}$ section of the orientation distribution function (ODF) is commonly used to describe texture in BCC metals, and the coordinate system is chosen to be similar to that used for rolling in the $\mathrm{y}$ direction with $\mathrm{z}$ being

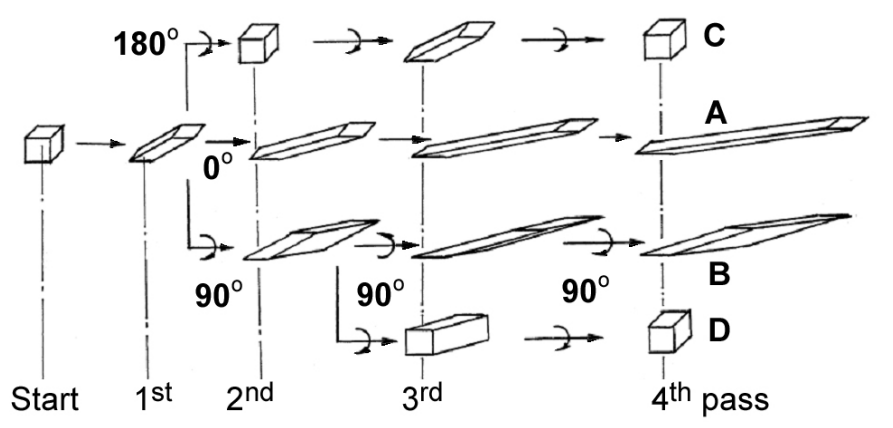

Figure 1 Simple shear history of an initial cubic element due to different ECAE deformation histories [1]
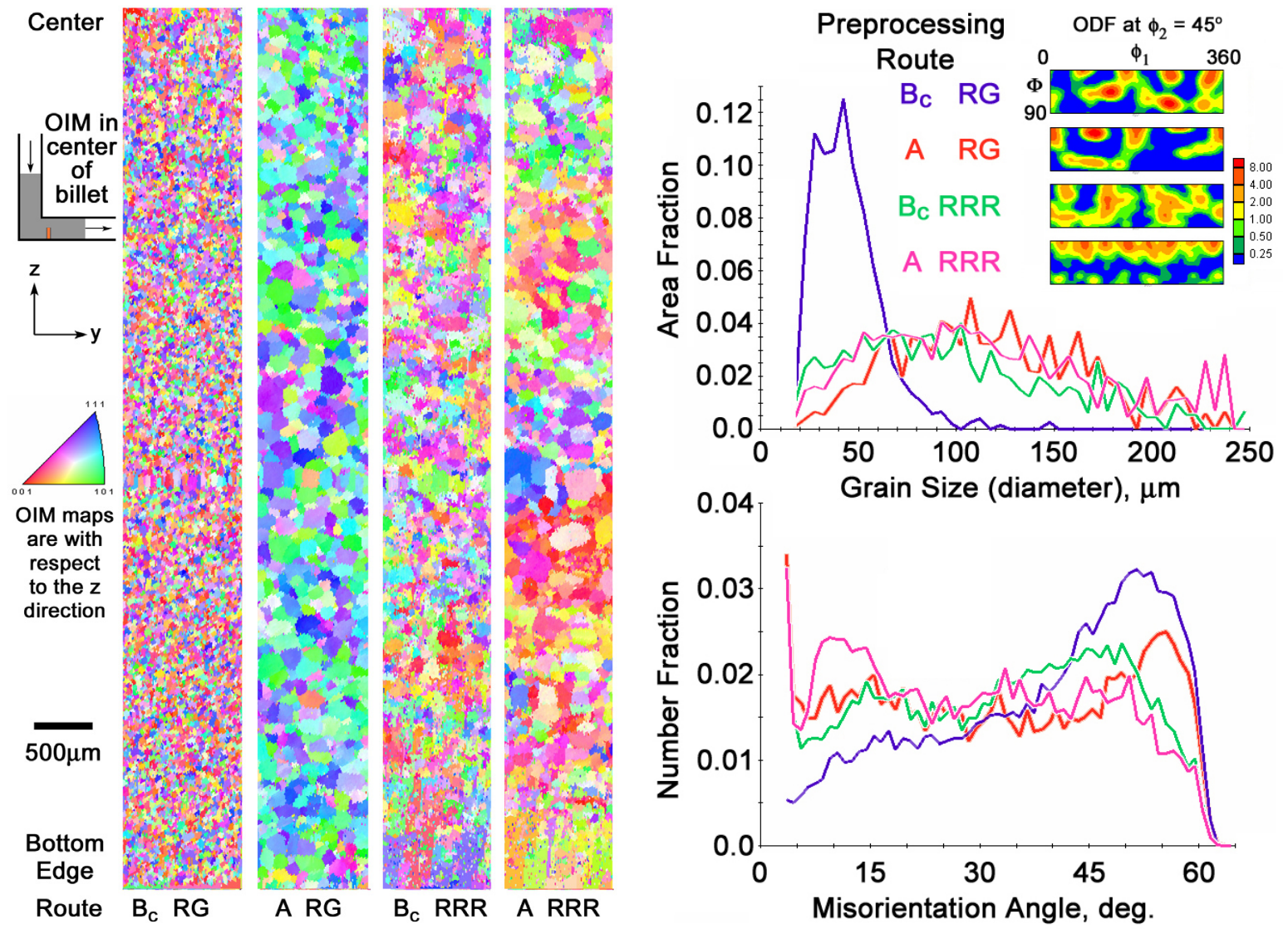

Figure 2 Three samples of microstructure and texture from preprocessing large grain $\mathrm{Nb}$ billets by different routes indicates that textures and grain sizes differ with processing path. 
similar to the rolling plane. The route $\mathrm{B}_{\mathrm{c}}$ sample shows a texture very unlike that of rolling, while the route A processing is somewhat similar to rolling (which will be illustrated with comparisons below). The misorientation distribution (purple line) is similar to a random misorientation distribution (though the texture is not random). Comparing RG with RRR material, the effect of lower impurity atom content clearly increases boundary mobility, as the $B_{c}$ grain size for the RRR material is similar to the A grain size. The textures of the RRR material are not similar to the RG material with the same processing paths, nor is the relative difference observed in the RG material similar, as grain size in the RRR material was similar with both paths. Furthermore the textures and misorientation characteristics are different for all four cases. Clearly, differences in alloy purity and processing history have large effects on resulting microstructure and texture.

After ECAE preconditioning, the bars were rolled from $25 \mathrm{~mm}$ to $4 \mathrm{~mm}$ thick sheet, using the same reduction schedule for all ECAE processed bars, but in some cases cross rolling was used. After rolling, the sheets were annealed again, with some exemplary results (of about 30 trials) shown in Figure 3. The OIM scan provides microstructure and texture information, indicating dramatic differences resulting from the starting billet condition. Clearly, different processing histories led to different final grain sizes and textures, with grain size ranging from 20 to 200 microns, depending on ECAE processing. In every case, the textures consisted of three components in different relative weights to each other. The blue orientation indicates orientations on the $\gamma$ fiber, which is a desirable orientation for obtaining stable deformation of sheet metal in large strain drawing or bulging operations. The $\alpha$ fiber is also present in some samples, but not others; compared to steels, the $\alpha$ fiber is remarkably weak. A rotated cube component is always present (has colors between red and pink on maps), but this component can be very weak or very strong, depending upon process history. The rotated cube component tends to split into two components in the RRR material (to provide an orientation of (4 6 30)[15 25 -7], or Bunge Euler angles $0^{\circ}, 14^{\circ}, 32^{\circ}$ ), whereas it is more smeared in the RG material. Also, it is nearly impossible to get an even distribution along the $\gamma$ fiber in the RRR material, while it is possible to obtain this in the RG material. It is remarkable that orientations with the 101 (green) direction in the normal direction are absent in all samples.

Commercially processed $\mathrm{Nb}$ is known for having texture gradients, and commonly having irreproducible textures. This work shows that ECAE preprocessing can reduce this tendency for some processing paths, making production of a much more homogeneous and reproducible material possible. However it is also possible to get texture gradients in ECAE processed material, so only with appropriate ECAE processing, can improved control or flexibility be attained to gain desirable textures and microstructures.

The presence of specific components of texture with larger and smaller volume fractions implies that there are specific relationships between activated slip systems and recrystallization mechanisms. To examine the process of recrystallization and its dependence on grain orientations, specimens that mimicked the process of cavity fabrication from single or multi crystal slices of an ingot were examined, and described in the next section.

\section{Welding of Deformed Single Crystals}

Because microstructures are inherently variable in rolled and recrystallized sheet, bypassing rolling entirely by slicing sheets from large multi-crystal ingots may be an effective strategy for making cavities. Though each of the grain orientations deform differently in biaxial drawing, leading to significant differential thinning and deformation resistance at grain 
boundaries that cause mild ridges, cavities made from these large grain slices have performed comparably with the best cavities made from polycrystals [2]. However, such deep drawn cavity

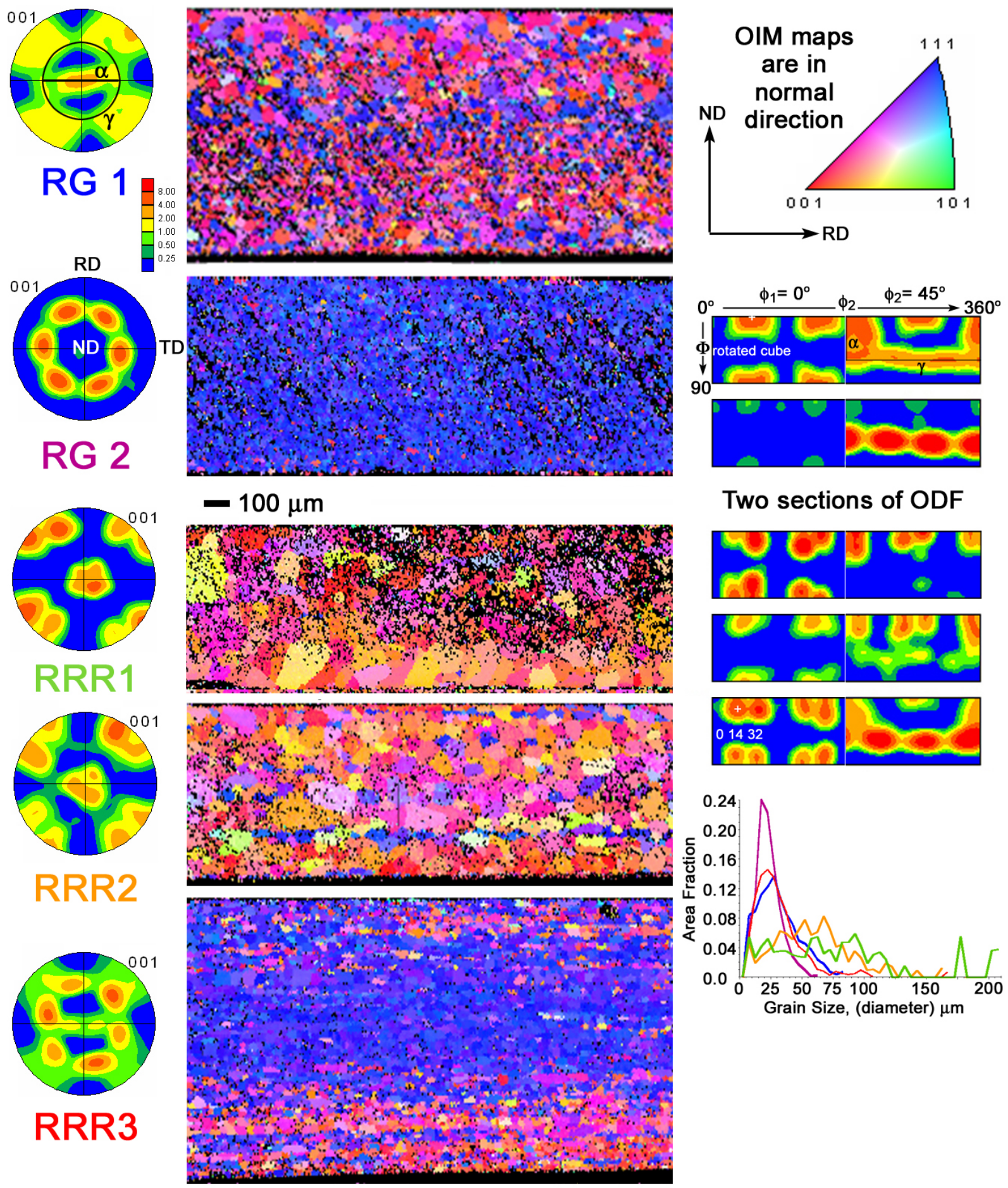

Figure 3 Texture and OIM maps of 5 examples of sheet that was rolled from preprocessed ECAE ingots with different deformation histories, and then annealed, results in different grain size distributions and texture gradients. The blue orientation is associated with the $\gamma$ fiber, and the red and pink orientations are related to a rotated cube component, and the $\alpha$ fiber is present in some but not all specimens. Varying ECAE processing paths causes different fractions of these three texture components to be present after a recrystallization anneal. 
halves must still be welded together. Because the welds occur in regions where the greatest strains develop during forming (and the highest electric and magnetic fields develop at these weld locations in operation), it is important to assess how much strain can be tolerated before generating recrystallization and recovery effects that may affect the functional properties of the deformed single or multi crystal material in beneficial or detrimental ways.

Three tensile specimens labeled A, C, F were cut from left over material used to make large-grain cavities, in order to investigate effects of strain and etching on surface finish and microstructure. Samples were chosen to have orientations with low index crystal directions close to the tensile axis and normal direction; for example, specimen A has the (110) plane close to the specimen normal direction and [001] nearly lined up with the tensile axis.

The processing history used, and its effect on surface roughness is indicated along the bottom axis of Figure 4: The specimens were electropolished so that the initial orientation could be determined using OIM. Then one half was etched using BCP to remove several 10's of microns of material (the protected half was covered with a polymer mask). Next, the samples were deformed to an engineering strain of 0.4 , which is comparable to the hoop tensile strain that occurs at the iris during deep drawing. Some samples etched more than others, so that the cross sectional areas were smaller on the etched half of the specimen. In particular, specimen A strained preferentially in the etched half, up to a strain of about $65 \%$, such that the unetched half only deformed to a strain of about $5 \%$. Figure 4 shows how surface roughness was affected at different stages of sample preparation. The roughness varied with specimen orientation and

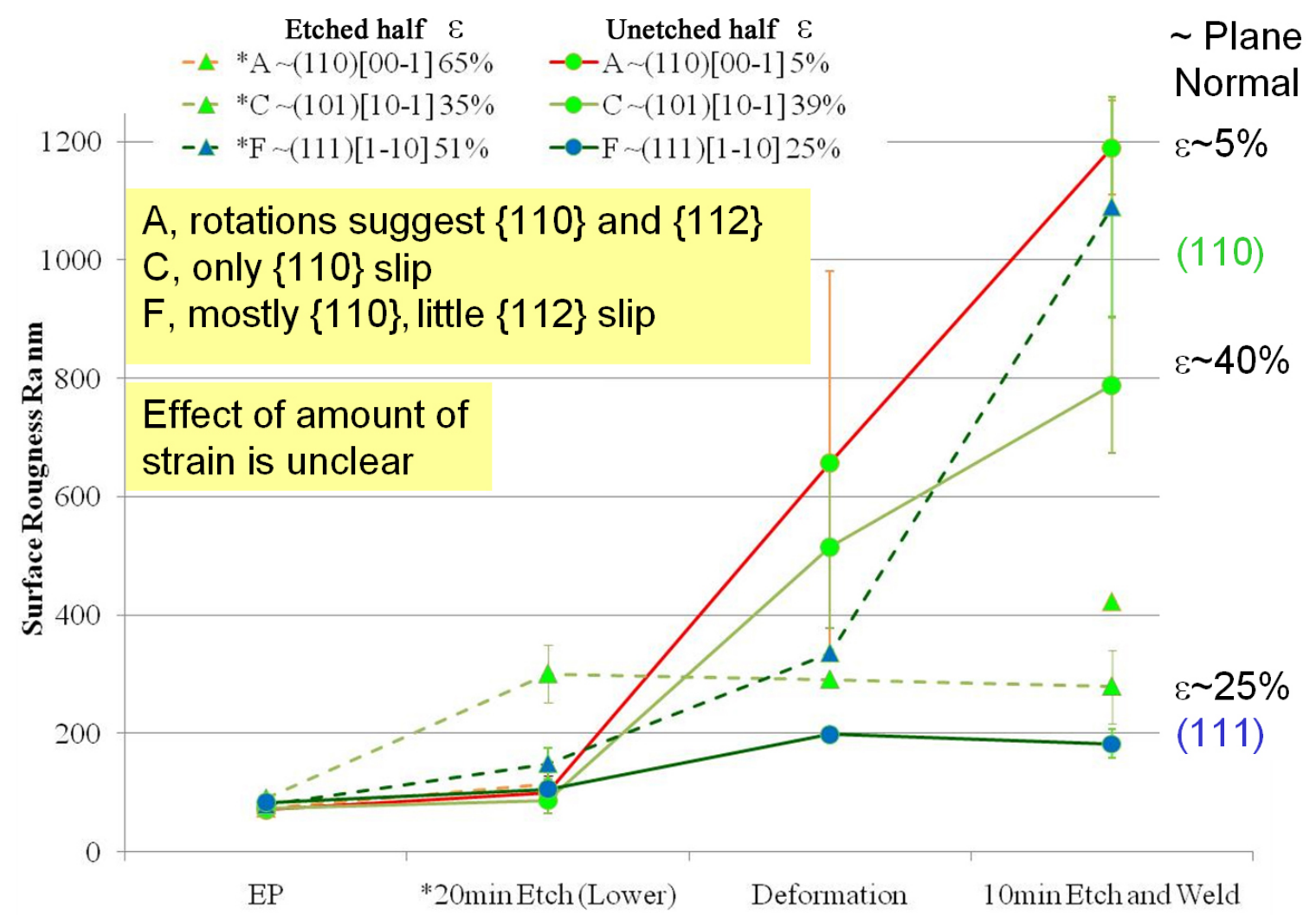

Figure 4 Effect of processing history on surface roughness for three different single crystal specimens. After deformation, specimens were cut in half and welded to a different half to examine effects of strain and crystal orientation on weld microstructure. 
became rougher with deformation and etching in ways that are self consistent with each other, but the relationships are complex, indicating that simple relationships between roughness and process history, strain, or crystal orientation are not simple.

Figure 5 shows engineering stress-strain relationships for the three crystals, indicating different deformation characteristics. To gain insight on what may account for the differences, the slip systems that operated were estimated using crystal plasticity finite element simulations with uniaxial deformation imposed on single elements. The shears on different slip systems are also shown in Figure 5, and the yield stresses and hardening parameters used were adjusted for the $\{110\}$ and $\{112\}$ families of slip systems in order to get approximate agreement with experimental data for all three specimens; slip on $\{112\}$ planes were given a $10 \%$ higher yield stress to follow several opinions in the literature. Clearly, the slip history differed in the three specimens, where specimen $\mathrm{C}$ exhibited single slip, whereas specimens A and $\mathrm{F}$ exhibited operation of slip on both $\{110\}$ and $\{112\}$ planes.

\section{Recrystallization and Recovery Phenomena}

Prior recrystallization studies in rolled sheet by Sandim [3,4], Jiang et al. [5] showed that recrystallization did not occur like IF (interstitial-free) steel [6-8]. Iron differs from $\mathrm{Nb}$ in having a transformation that generates very fine carbides, but like pure $\mathrm{Nb}$, it has a low interstitial content. The recrystallized texture of $\mathrm{Nb}$ was much weaker, suggesting that there are no strongly preferred recrystallization orientations in $\mathrm{Nb}$. One of the possible reasons for this difference is that the elastic anisotropy of $\mathrm{Nb}$ and $\mathrm{Fe}$ are opposite of each other, as shown in Figure $6[9,10]$. The contribution of elastic modulus to recrystallization has been identified by Lee as having a strong impact on recrystallized grain growth in many materials $[11,12]$, which is

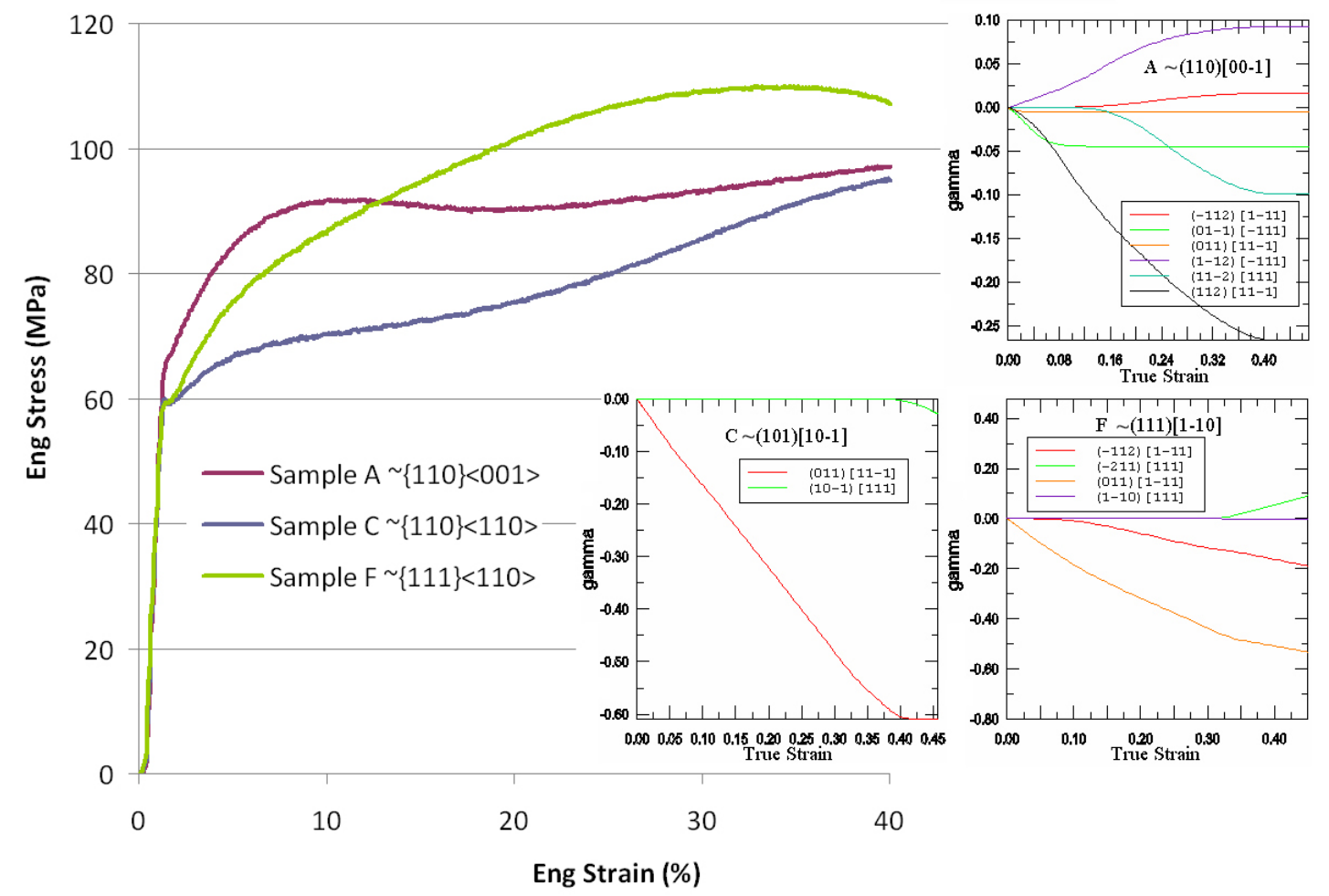

Figure 5 True stress-strain curves based upon assumption of uniform strain, with crystal plasticity finite element simulations of deformation in the three specimens A, C, F were used to identify which slip systems were most highly favored to operate. 

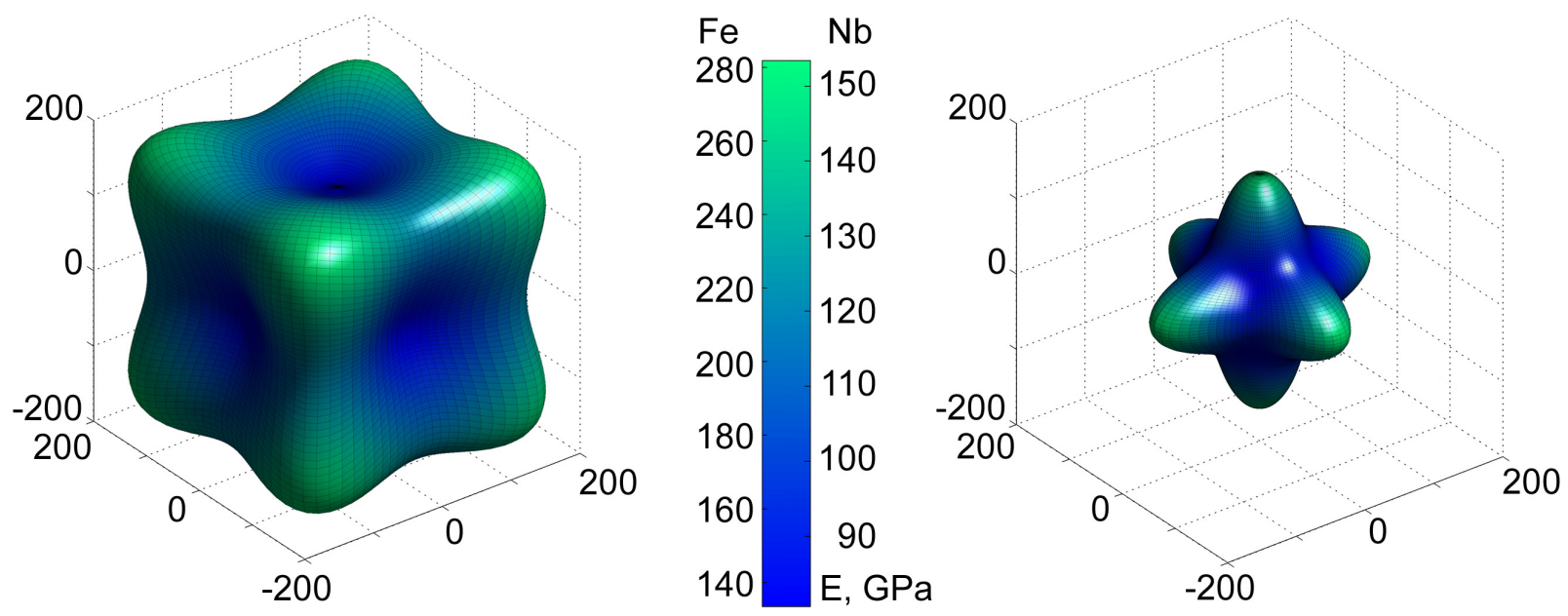

Figure 6 Young's modulus as a function of crystal direction for $\mathrm{Fe}$ and $\mathrm{Nb}$. $\mathrm{Nb}$ is the most compliant of the $\mathrm{BCC}$ metals; Fe and $\mathrm{Nb}$ bound the elastic anisotropy that is observed in pure BCC metals.

typically not considered in other studies of recrystallization in Fe [6-8]. Lee's maximum strain energy release model predicts that a recrystallized grain will lower elastic strain energy most by aligning a crystallographic minimum stiffness (E, Young's modulus) direction with the absolute maximum internal stress direction. The maximum internal stress direction is found from the cold-worked state, and taken to be the slip direction, if only one slip system is dominant, or the vector sum of the slip directions if more than one is highly active [12]. This implies that recrystallization depends not only on plastic but elastic properties as well. In the prior year's report, an early sample was evaluated to determine if this model works, and it did. This model was evaluated again for the specimens described above.

From observation of a weld joint between two multi-crystal half cells in Figure 7, recrystallization occurs along a weld, and differently on the two sides. The heat affected zones on either side have grains that are larger on the left side than the right side. In the fusion part of the weld, there is a well defined difference in crystal orientation on the left (brigher) and right (darker) sides, with a smoothly wavering boundary.

Figure 8 shows the three welded single crystal specimens described above, with inverse pole figure maps above and kernel average misorientation (lattice curvature) maps below. Three weld conditions were used, with too much heat so the weld did not form, when there was a full penetration weld, and when there was a partial penetration weld. In each case, new orientations formed, which differed from the initial orientations. The initial orientations are shown with the large unit cell prism on the left and right sides, and the smaller overlaid prisms illustrate the orientation where the prism is located. Examination of the associated inverse pole figures shows that the peak spread is

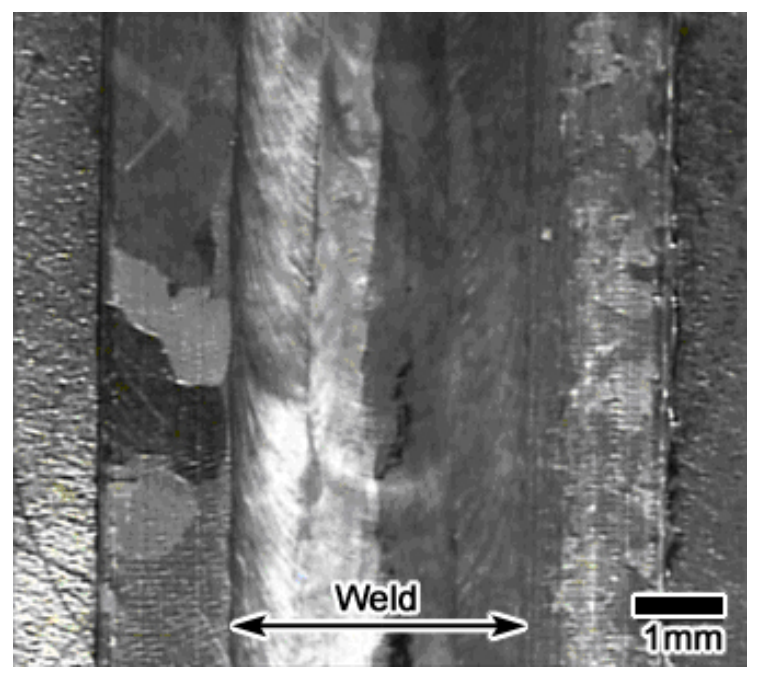

Figure 7. Recrystallization in the heat affected zone is evident on either side of the fusion zone in an equatorial weld of two multi-grain half cells. 
greater in the recovered regions than the recrystallized regions, indicating retention of significant low angle boundary/dislocation networks in recovered regions. In the recovered regions, the orientation is nearly the same as the initial orientation. There are low angle boundaries in both recovered and recrystallized grain regions that are made evident in the kernel average misorientation maps. Clearly, the recrystallized grains have fewer orientation gradients (blue, rather than green, indicates more nearly perfect crystals) than the recovered grains, implying that there is a larger geometrically necessary dislocation content in recovered grains.

Recrystallization differed in each specimen, according to the crystal orientations and dislocation populations present after deformation. Pole figures in Figure 9 and summary details from others in Table II indicate that recrystallized grains have rotations mostly about the 112 poles of their respective recovered orientations. As there is a $<112>$ direction perpendicular to the $<111>$ Burgers vector on $\{110\}$ planes (and similarly for $<110>$ directions when slip occurs on $\{112\}$ planes), it is possible that nuclei may have developed from local rotations associated with shear banding. This is also supported by the simulation of orientation $\mathrm{C}$, which predicts slip activity only on a $\{110\}$ slip system, and the recrystallized rotation observations were about 112 poles. In other specimens, where some mixed $\{110\}$ and $\{112\}$ activity was predicted, there are some recrystallized orientations about both 110 and 112 that are consistent with shear bands as an orientation nucleus; in F only one of the four recrystallized grains rotated

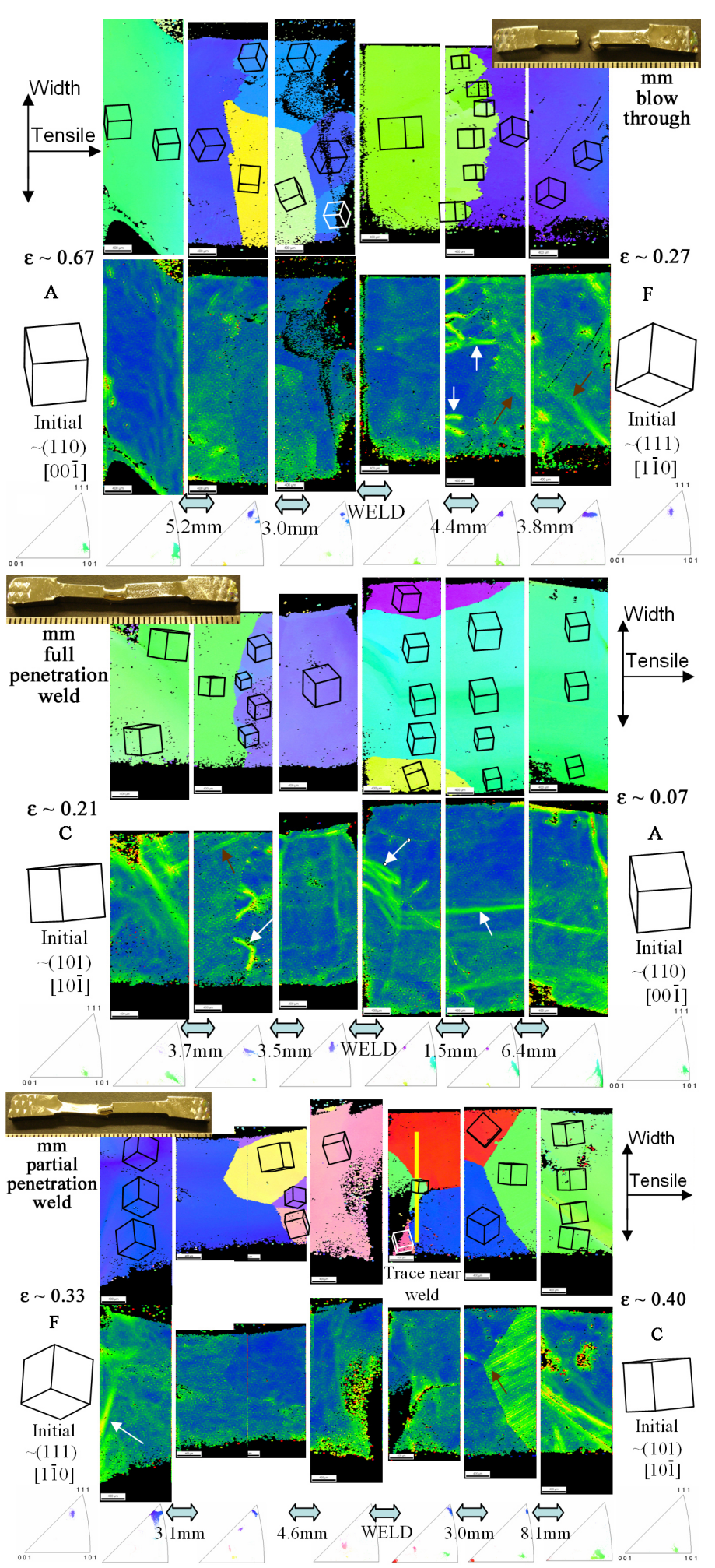

Figure 8 Normal direction inverse pole figure maps and kernel average misoriention maps (below), with discrete point inverse pole figures for the three welded specimens. 
about $<110>$, consistent with lower activity of $\{112\}$.

As an alternative and perhaps complimentary approach, prediction of maximum released strain energy was also computed using the methods described in [13] and our progress report from last year, and tabulated in Table I. To examine the relationship between elastic anisotropy and recrystallization, the maximum strain energy release model was used [12]. This model is based on the release of stored elastic strain energy acquired during deformation, which is maximized if a recrystallized grain has a low Young's modulus crystal direction along the former maximum internal stress direction. The maximum internal stress direction is determined by taking the vector sum of all presumed-active slip systems. Three cases were chosen to calculate the maximum internal stress direction from the deformed orientations of the samples: 1) Any of the 48 slip systems with Schmid factor greater than 0.4 would be active, 2) any of the $\{110\}$ or $\{112\}$ systems with Schmid factor greater than 0.4 (since $\{123\}$ is not considered to be active until high strains $>60 \%$ [14-16], and only the top two highest Schmid factor $\{112\}$ planes (as elementary slip in BCC can occur on $\{112\}$ planes, except orientations in which anomalous slip is

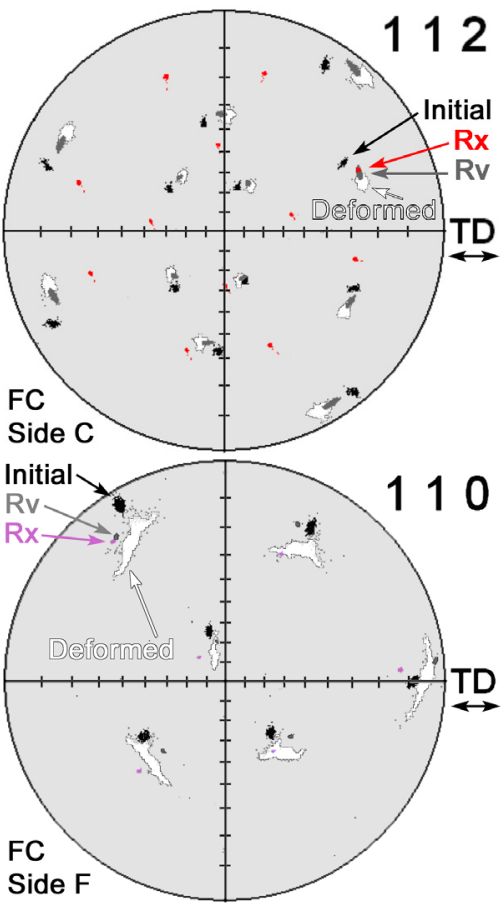

Figure 9 Sample pole figures showing orientation relationships at different stages of processing. possible [12]).

In case (1), where any of the $\{110\},\{112\}$, or $\{123\}$ systems with Schmid factors $>0.4$ were activated, the maximum elastic strain energy release model is consistent with the results, as all recrystallized grains are more compliant in the former maximum internal stress direction. Indeed, the model's prediction holds in all but a few cases, and those 'violations' occur only in specimen A, when $\{123\}$ was assumed to be inactive, but this particular specimen had over $60 \%$ strain, so this assumption may not be appropriate. In the other half of $\mathrm{A}$, having only $7 \%$ strain, the stored dislocation strain energy may not have been large due to the smaller strain, and it is clear that the majority of the specimen recovered rather than recrystallized.

\section{Role of dislocations in SRF Cavity Functional Properties}

An open question in the SRF community at the moment is to identify the role of dislocation substructure on functional properties of a cavity, specifically flux penetration [17] and thermal conductivity [18-19] (Figure 10 illustrates how thermal conductivity and RRR can be affected by deformation and annealing). Figure 11 illustrates electron channeling contrast images (ECCI) of dislocation structure in $\mathrm{Nb}$ in two states, as-received ingot, and in a recrystallized grain. The contrast variation, and especially the bright contrast, represents the location of localized lattice curvature associated with dislocation cores, and hence the location of dislocations in the near-surface region. In the as-received ingot, there are regions with very high density, and regions that appear to be free of dislocations. In contrast, a recrystallized specimen has a much more uniform contrast variation, but the magnitude of the difference is not known from these initial exploratory images, as the contrast adjustments used to make a good image were different. On a larger scale, the differences between as-received, deformed, recovered, and recrystallized grains show significant differences in peak spreading in the inverse pole figures. 
These results show that dislocation content varies dramatically with different stages of the manufacturing process.

Figure 13 [13] illustrates how diffraction peaks vary in recrystallized vs. recovered grains just adjacent to the weld in specimen FC (where the yellow line trace is shown in Figure 8). This specimen shows that the nucleation of the red and blue recrystallized grains occurred some distance from the fusion interface, and grew into the solidifying weld. However, a remnant of the (green) deformed orientation survived and resisted being consumed by recrystallized grains, and grew into the fusion zone as well. There is ongoing work to take full advantage of the 3-D x-ray analysis capability in collaborative work with G.E.

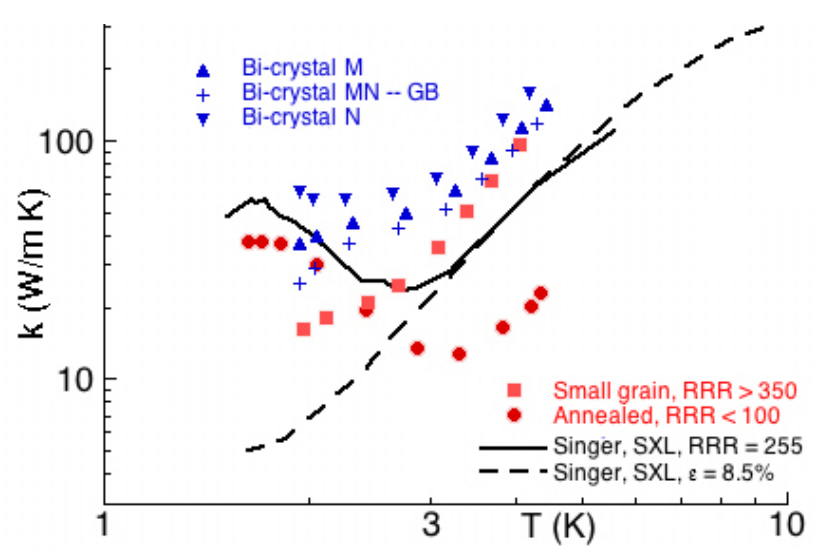

Figure 10 - Thermal conductivity measurements in polycrystals show sensitivity to RRR, heat treatment, and dislocation content; annealing can lead to recovery of the high $\mathrm{k}$ phonon peak at low temperatures, but it can also introduce impurities that degrade $\mathrm{k}$ at higher temperatures. Grain boundaries can also inhibit thermal conduction.

Ice and R. Barabash at ORNL Preliminary results indicate that strain in the shoulder region of specimen C, consists of dislocations in cell interiors that are on 112 planes, while the cell walls consist of 110 dislocations; further study of this will provide understanding of how how dislocations are generated and change character during deformation and recovery.
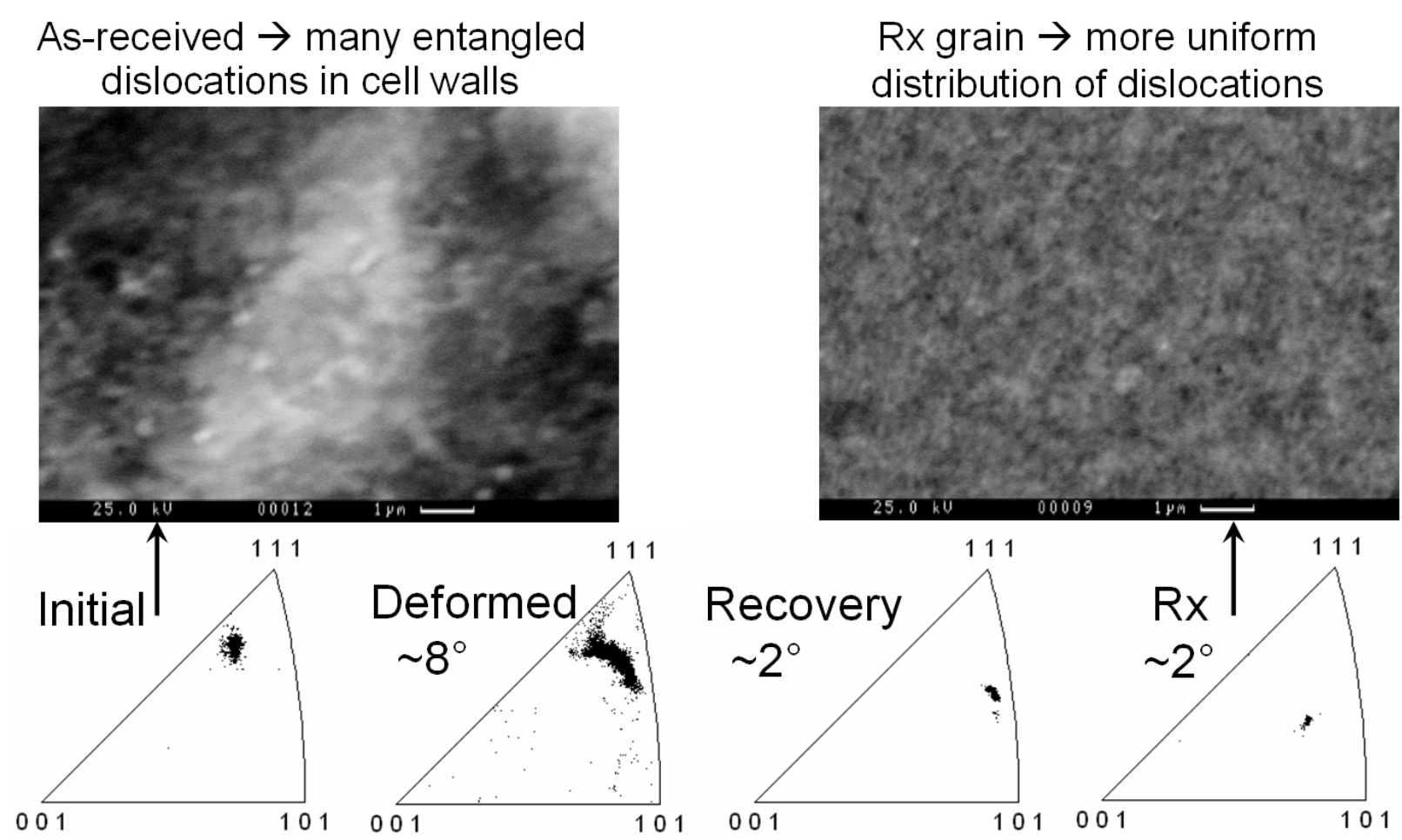

Figure 11 Dislocation structure is compared in four stages of processing using electron channeling contrast imaging and inverse pole figure maps from OIM scans. Peak spread is greatest in the deformed state. 


\section{Conclusion}

Issues related to the evolution of microstructure and defect content are a continuing topic of interest, and the foundations developed in the experimental and modeling work described above will facilitate further development of a scientific basis for making decisions to optimize processing of SRF cavities in the future, which is necessary before accelerators that require large numbers of cavities will be built. These results and a number of others from related efforts at MSU and elsewhere are summarized in a tutorial lecture on the physical and mechanical metallurgy of niobium given at the 2008 Materials Workshop, which can be accessed at http://meetings.nscl.msu.edu/srfmatsci/index.php?id=conference_details/Wednesday.php.

\section{References:}

1. Segal VM, Engineering and commercialization of equal channel angular extrusion (ECAE), Materials Science and Engineering A386, 269-76, 2004.

2. Kneisel, P, Myneni, GR, Ciovati, Sekutowicz, GJ, Carneiro, T, Preliminary Results From Single Crystal and Very Large Crystal Niobium Cavities, in Proceedings of the 2005 Particle Accelerator Conference, p. 3991-3993, 2005.

3. Sandim HRZ, Lins JFC, Pinto AL, Padilha AF. Recrystallization behavior of a cold-rolled niobium bicrystal. Mat. Sci. Eng., A354, $217-$ 228, Elsevier 2003.

4. Sandim, HRZ; Raabe, D, EBSD study of grain subdivision of a Goss grain in coarse-grained cold-rolled niobium, Scripta Materialia, 53 (2) 207-212 2005.

5. Jiang, H, Bieler, TR, Compton, C, Grimm, TL, Cold Rolling Evolution in High Purity Niobium Using a Tapered Wedge Specimen $\left(12^{\text {th }}\right.$ International workshop on RF Superconductivity (SRF 2005)), Physica C 441 (2006), pp. 118-21.

6. Barnett MR, Kestens L, Formation of $\{111\}<110>$ and $\{111\}<112>$ textures in cold rolled and annealed IF sheet steel, ISIJ International 39(9), 923-929 1999

7. Choi SH, Cho JH, Primary recrystallization modelling for interstitial free steels, Materials Science and Engineering A 405 (1-2), 86-101, 2005.

8. Park YB, Lee DN, Gottstein G, Evolution of recrystallization textures from cold rolling textures in interstitial free steel, Materials Science and Technology 13 (4), 289-298 1997.

9. Armstrong, PE, Dickinson, JM and Brown, HL, Temperature dependence of the elastic coefficients of niobium (columbium) Trans. Metal. Soc. AIME 236, 1404-8, 1966.

10. Hearmon, RFS, The elastic constants of anisotropic materials, Rev. Mod. Phys, 18, 409-440, 1946.

11. Park YB, Lee DN, Gottstein G, Evolution of recrystallization textures from cold rolling textures in interstitial free steel, Materials Science and Technology 13 (4), 289-298 1997.

12. Lee DN, Relationship between deformation and recrystallization textures of fcc and bec metals, Philosophical Magazine 85 (2-3), 297322, 2005.

13. Baars D, Jiang H, Bieler TR, Zamiri A, Pourboghrat F, and Compton C, Effects of Elastic Modulus on Deformation and Recrystallization of

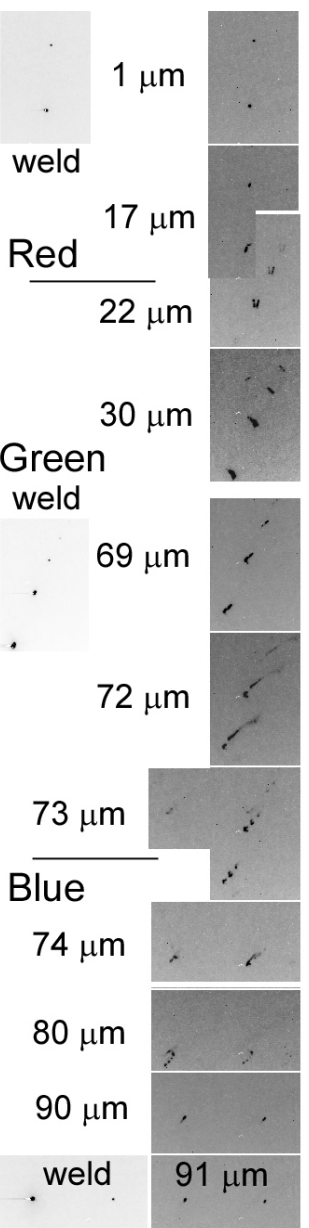

Figure 12 Synchrotron Laue peaks of Rx red, prior green, and Rx blue orientation adjacent to weld in sample $\mathrm{FC}$ on the $\mathrm{C}$ side (along yellow line in Figure 8) - note streaked patterns in recovered green grain and recrystallized blue grain several $\mu \mathrm{m}$ from the greenblue grain boundary. 
High Purity Nb, Applications Of Texture Analysis, A Collection of Papers Presented at the 15th International Conference on Texture in Materials (ICOTOM 15), June 1-6, 2008, Pittsburgh, Pennsylvania, Chief Editor, AD Rollett, Ceramic Transactions, Volume 201, American Ceramic Society, Westerville, Ohio 43082, 2008, pp. 391-98.

14. Bowen DK, Christian JW, Taylor G, 1967. Deformation Properties of Niobium Single Crystals. Can. J. Phys., 45, 903.

15. Raabe D, Lucke K, Rolling Textures of Niobium and Molybdenum. Z. Metallkunde 85(5) 302-306, 1994.

16. Seeger A, Wasserbach W, Anomolous Slip- A feature of high purity Body-Centered metals. Phys. Stat. Sol. (a), 189 No. 1, 27-50, 2002.

17. Ciovatil G and Gurevich A, Evidence of high-field radio-frequency hot spots due to trapped vortices in niobium cavities Physical Review Special Topics - Accelerators and Beams 11, 122001 (2008).

18. Singer W, Brinkmann A, Ermakov A, Iversen J, Kreps G, Matheisen A, Proch D, Reschke D, Singer X, Spiwek M, Wen H, Brokmeier H-G, Large Grain Superconducting RF Cavities at DESY, LINAC 2006, Knoxville, Tennessee, August 21-26, 2006.

19. Ahmad Aizaz, Pierre Bauer, Terry L. Grimm, Neil T. Wright, and Claire Z. AntoineMeasurements of Thermal Conductivity and Kapitza Conductance of Niobium for SRF Cavities for Various Treatments, IEEE Transactions on Applied Superconductivity 17(2), 2007, 1310-13.

\section{Papers published based upon this research}

Effects of Elastic Modulus on Deformation and Recrystallization of High Purity Nb, D. Baars, H. Jiang, T.R. Bieler, A. Zamiri, F. Pourboghrat, and C. Compton, Applications Of Texture Analysis, A Collection of Papers Presented at the 15th International Conference on Texture in Materials (ICOTOM 15), June 1-6, 2008, Pittsburgh, Pennsylvania, Chief Editor, A.D. Rollett, Ceramic Transactions, Volume 201, American Ceramic Society, Westerville, Ohio 43082, 2008, pp. 391-98.

Processing strategies for niobium sheet used in advanced superconducting particle accelerator cavities, D. Baars, T. R. Bieler, K. T. Hartwig, H. Jiang, C. Compton and T. L. Grimm, JOM 59(6), pp 50-55, (June 2007).

Studies of Alternative Techniques for Niobium Cavity Fabrication, C. Compton, D. Baars, T. Bieler, J. Bierwagen, S. Bricker, D. Pendell, R. York, Proceedings of 13th International workshop on RF Superconductivity (SRF 2007) Beijing, China, Oct. 14-19, 2007.

Crystal Orientation Effects During Fabrication of Single or Multi-Crystal Nb SRF Cavities, D. Baars, T.R. Bieler, A. Zamiri, F. Pourboghrat, C. Compton, Proceedings of 13th International workshop on RF Superconductivity (SRF 2007) Beijing, China, Oct. 14-19, 2007.

Crystal Orientations Near Welds in High RRR Niobium with Large Grains, D. Baars, H.Jiang, T.R.Bieler, C. Compton, T.L. Grimm, IEEE Transactions on Applied Superconductivity 17(2), pp. 1295-1298, (2007).

Microstructural refinement of niobium for superconducting RF cavities, K.T., Hartwig, J. Wang, D.C. Baars T.R. Bieler, S.N. Mathaudhu, R.E. Barber, IEEE Transactions on Applied Superconductivity 17 (2), pp. 13051309, (2007).

\section{Presentations given based upon this research}

12. Recrystallization and recovery in niobium, D.C. Baars, T.R. Bieler, SRF Materials Workshop, Michigan State University, October 29 - October 31, 2008.

11.* Physical and Mechanical Metallurgy Lexicon, invited tutorial lecture, T.R. Bieler, SRF Materials Workshop, Michigan State University, October 29 - October 31, 2008, http://meetings.nscl.msu.edu/srfmatsci/index.php?id=conference_details/Wednesday.php. 
10. Crystal Orientation Effects on Welding of Single or Multi-Crystal Nb SRF Cavities, D. Baars, T.R. Bieler, A. Zamiri, F. Pourboghrat, C. Compton, G.E. Ice R. Barabash, W. Liu, Applied Superconductivity Conference, Chicago, Illinois U.S.A., August 17 - 22, 2008.

9.* Effects of Ingot Crystal Orientation on Deformation, Welding, and Recrystallization in High RRR Nb, T.R. Bieler, Derek Baars, Hairong Jiang, Amir Zamiri, Farhang Pourboghrat, Neil T. Wright, K.T. Hartwig, Chris Compton, Invited seminar, Superconducting Cavities Metallurgy Group DESY (Deutsches ElecktronenSynchrotron), Hamburg, Germany, 18 Aug 2008.

8. Textures in Nb Processed by Equal Channel Angular Extrusion, S. Balachandran, K. T. Hartwig, R. B. Griffin, T. Bieler, D. Baars, ICOTOM 15, Carnegie Mellon University, June 1-6, 2008.

7. Effects of Elastic Modulus on Deformation and Recrystallization of High Purity Nb, D. C. Baars, H. Jiang, T. R. Bieler, A. Zamiri, C. Compton, F. Pourboghrat, K. Hartwig, ICOTOM 15, Carnegie Mellon University, June 1-6, 2008.

6. Anisotropic Yield Function for Modeling Formability of Conventionally Rolled RRR Niobium, Amir Zamiri, Hairong Jiang, Thomas Bieler, Farhang Pourboghrat, Chris Compton, TMS Annual Meeting, New Orleans, LA, March 10-13, 2008.

5. Consequences of Crystal Orientation on Fabricating Single or Multi-Crystal Nb SRF Cavities, Derek Baars, Thomas Bieler, Amir Zamiri, Farhang Pourboghrat, Chris Compton, TMS Annual Meeting, New Orleans, LA, March 10-13, 2008.

4. Crystal orientation effects during fabrication of single or multi-crystal Nb SRF cavities, D. Baars, T.R. Bieler, A. Zamiri, F. Pourboghrat C. Compton, 13th International Workshop on RF Superconductivity Peking University, Beijing, China 2007, Oct 14-19, 2007.

3. Preliminary investigation of a model for predicting recrystallization in Nb, D. Baars, H. Jiang, T.R. Bieler, C. Compton, T. Grimm, SRF materials workshop, Fermi National Accelerator Laboratory, Batavia, IL, May 2324, 2007.

2. Comparing ECAE and Rolling of Niobium, D.Baars, T.R. Bieler, K.T. Hartwig, Refractory Metals 2007, TMS Annual Meeting, Orlando, Fl, February 26, 2007.

1. Crystal orientations near welds in high RRR Niobium with very large grains, D. Baars, H. Jiang, T. Bieler, C. Compton, P. Bauer, T. Grimm, Proceedings of the Applied Superconductivity Conference, Seattle, August 29-Sept 1, 2006, IEEE. 